\title{
KHARAKTERISTIK BALITA DAN SOSIO DEMOGRAFI BERHUBUNGAN DENGAN STATUS GIZI BALITA DI WILAYAH KERJA PUSKESMAS MENCIRIM KECAMATAN SUNGGAL TAHUN 2014
}

\author{
Rina Doriana Pasaribu \\ Jurusan Kebidanan Poltekkes Kemenkes Medan
}

\begin{abstract}
Abstrak
Fenomena kurang gizi disebabkan kombinasi faktor, kemiskinan, lingkungan,buruknya pelayanan kesehatan balita khususnya promosi pemberian ASI Eksklusif pada bayi, pemberian MP-ASI tidak benar dan kurangnya pengetahuan ibu mengenai pedoman umum gizi seimbang. Berdasarkan permasalahan tersebut maka tujuan penelitian adalah untuk mengetahui faktor yang berhubungan dengan status gizi balita di wilayah kerja Puskesmas Mencirim Kecamatan Sunggal. Penelitian ini bersifat survey analitik dengan pendekatan Cross Sectional. Populasi dalam penelitian ini adalah semua ibu yang memiliki balita dengan sampel 102 orang ibu balita. Pengambilan data dilakukan dengan metode wawancara dengan menggunakan kuesioner. Uji statistik yang digunakan adalah $C h i$ Square untuk mencari hubungan antara variabel independen dan dependen. Hasil penelitian menunjukkan ada hubungan antara status imunisasi dengan status gizi balita $p=0,001$, ada hubungan antara status ASI Eksklusif dengan statu gizi balita $p=0,017$, ada hubungan antara tingkat pendidikan dengan status gizi balita $p=0,000$, ada hubungan antara pendapatan keluarga dengan status gizi balita $p=0,006$, ada hubungan antara status pekerjaan ibu dengan status gizi balita $p=0,010$, tidak ada hubungan antara jumlah anak dengan status gizi balita $p=0,587$. Di saran kepada Puskesmas Mencirim agar dapat memberikan penyuluhan kepada masyarakat untuk dapat meningkatkan status gizi balita, bagi ibu-ibu agar memperhatikan pola kebutuhan anaknya selama masa pertumbuhannya dengan memenuhi kebutuhan gizi pada seribu hari kehidupan pertama.
\end{abstract}

Kata kunci: Status gizi, balita

\section{Latar Belakang}

Keberhasilan pembangunan suatu bangsa ditentukan oleh ketersediaan sumber daya manusia (SDM) yang berkualitas, yaitu SDM yang memiliki fisik yang tangguh, mental yang kuat, kesehatan yang prima, serta cerdas. Bukti empiris menunjukkan bahwa hal ini ditentukan oleh status gizi yang baik. Oleh karena itu masalah gizi kurang dan buruk yang dalam model unicef (1990) di indentifikasi dipengaruhi langsung oleh pola asuh, ketersediaan pangan, faktor sosial ekonomi budaya politik, dapat menjadi faktor penghambat dalam pembangunan nasional (Dinkes, 2006).

Di Indonesia persoalan gizi anak usia balita menjadi masalah serius pada sebagian besar kabupaten/kota. Menurut Profil kesehatan Indonesia tahun 2007 terdapat 18,4\% anak balita yang kekurangan gizi, terdiri dari gizi kurang $13,0 \%$ dan gizi buruk 5,4\%. Fenomena kurang gizi disebabkan kombinasi faktor, kemiskinan, lingkungan,buruknya pelayanan kesehatan balita khususnya promosi pemberian ASI Eksklusif pada bayi, pemberian MP-ASI tidak benar dan kurangnya pengetahuan ibu mengenai pedoman umum gizi seimbang (Adisasmito,2010). Gizi kurang dan gizi buruk pada balita dapat mengakibatkan terganggunya pertumbuhan dan perkembangan fisik, mental dan spiritual. Bahkan pada bayi, gangguan tersebut dapat bersifat permanen dan sangat sulit untuk diperbaiki. Kekurangan gizi pada balita apabila dibiarkan tentunya mengakibatkan balita sulit berkembang (Syarief, 2004).

Masalah gizi semula dianggap sebagai masalah kesehatan yang hanya dapat ditanggulangi dengan pengobatan medis atau kedokteran, namun, disadari bahwa gejala klinis gizi kurang yang banyak ditemukan dokter ternyata adalah tingkatan akhir yang sudah kritis dari serangkaian proses lain yang sudah mendahuluinya, sekarang telah diketahui bahwa gejala klinis gizi kurang adalah akibat ketidak seimbangan yang lama antara manusia dan lingkungan hidupnya. Lingkungan hidup ini mencakup lingkungan alam, biologis, sosial budaya maupun ekonomi, masing-masing faktor tersebut mempunyai peran yang kompleks dan berperan penting dalam etiologi penyakit gizi kurang (Susanto, 2004).

Kasus gizi buruk saat ini menjadi sorotan utama pada masalah kesehatan masyarakat di Indonesia, berbagai upaya sudah dilakukan bahkan salah satu tujuan Rencana Pembangunan Jangka Menengah Nasional (RPJMN) 2005- 2009 bidang kesehatan adalah menurunkan prevalensi gizi kurang menjadi setinggi-tingginya $20 \%$, termasuk prevalensi gizi buruk menjadi setinggi-tingginya 5\% pada 2009 (Sholihin, 2007). Indonesia sebenarnya 
sudah banyak membuat kemajuan dalam menekan angka gizi buruk dan gizi kurang pada anak balita, sebanyak $37,5 \%$ (1989), 35,5\% (1992), 31,6\% (1995), 29,5\% (1998), $26,4 \%$ (1999), dan 24,6\% (2000). Namun sejak tahun 2000, angka gizi buruk dan gizi kurang kembali meningkat, menjadi 26,1\% (2001), 27,3\% (2002), 27,5\% (2003),dan 29\% (2005). Sementara pada awal tahun 2005, menurut Survei Sosial Ekonomi Nasional (SUSENAS), jumlah kasus gizi buruk dan gizi kurang berturut-turut 8,8 $\%$ dan $19,20 \%$. Jumlah balita yang menderita gizi kurang dikatakan menurun menjadi 4,6 juta balita. Demikian pula balita yang menderita gizi buruk menurun menjadi 1,2 juta balita, dan balita yang menderita gizi buruk tingkat berat (busung lapar) menurun menjadi 120.000 balita (Sholihin, 2007).

Gizi buruk (severe malnutrion) adalah suatu istilah teknis yang umumnya dipakai kalangan gizi. Menurut Depertement Kesehatan( 2004), pada tahun 2003 terdapat sekitar 27,5\% (5 juta balita kurang gizi),3,5juta anak $(19,2 \%)$ dalam tingkat gizi kurang dam 1,5 juta anak gizi buruk (8,3\%). WHO (1999) mengelompokkan wilayah berdasarkan prevelensi gizi kurang kedalam 4 kelompok yaitu:rendah $(<10 \%)$, sedang ( $10-19 \%)$, tinggi $(20-29 \%)$ dan sangat tinggi ( $=>30 \%)$ (WHO, 2008).

Jumlah balita penderita gizi buruk di Medan saat ini sekitar 124 orang dan 1.896 anak mengalami gizi kurang yang terdapat di 14 kelurahan yang dikategorikan rawan pangan dengan jumlah keluarga miskin mencapai 2.599 kepala keluarga. Hal ini menumbuhkan perhatian serius semua pihak(Pemko Medan,2012).Menurut Hasil Survey FKM USU 2008 kasus gizi buruk mencapai 4,4\% dan gizi kurang 18,8\% masih cukup tinggi. Buktinya jumlah desa terbanyak dengan kasus gizi buruk terjadi di Kabupaten Nias selatan sebanyak 89 desa, Mandailing natal (78 desa),Deli serdang (67 desa), Humbahas( 58 desa) (Ramadhan,2010).

Peran tenaga kesehatan dalam penanganan gizi buruk di puskesmas hanya pemberian makanan tambahan dan tidak ada pemantauan tindak lanjut pada penderita gizi buruk. Salah faktor yang mempengaruhi status gizi pada balita diantaranya adalah pendapatan keluarga. Pendapatan yang rendah menyebabkan orang tidak mampu membeli pangan dalam jumlah yang diperlukan (Sholihin, 2007). Berdasarkan penelitian yang dilakukan oleh Andarwati (2007) di desa Purwojati kabupaten Wonosobo mendapatkan ada hubungan antara pendapatan keluarga dengan status gizi balita, $75 \%$ balita berstatus gizi baik berasal dari masyarakat berpenghasilan tinggi. Dalam penelitian ini penulis tertarik untuk meneliti tentang "Faktor yang Berhubungan dengan Status Gizi Balita di wilayah kerja Puskesmas Mencirim Kecamatan Sunggal".

\section{Perumusan Masalah}

Status gizi adalah keadaan tubuh sebagai akibat konsumsi makanan dan penggunaan zat-zat gizi. Penelitian yang dilakukan oleh Dewi (2007) menunjukkan bahwa responden yang memiliki status gizi kurang berasal dari keluarga yang berpenghasilan rendah, sedangkan yang memiliki status gizi baik berasal dari keluarga yang berpenghasilan tinggi. Penelitian oleh Arif (2006) menunjukkan ada hubungan antara Ibu yang bekerja dengan status gizi balita. Balita yang menderita kurang gizi lebih banyak ditemukan pada Ibu yang bekerja. Berdasarkan latar belakang diatas, maka dapat dirumuskan permasalahan penelitian adalah faktor apa saja yang berhubungan dengan status gizi balita di wilayah kerja Puskesmas Mencirim Kecamatan Sunggal tahun 2014.

\section{Tujuan Penelitian \\ Tujuan Umum}

Untuk mengetahui faktor yang berhubungan dengan status gizi balita di wilayah kerja Puskesmas Mencirim Kecamatan Sunggal tahun 2014.

\section{Tujuan Khusus}

1. Untuk mengetahui hubungan antara karakteristik balita (status imunisasi, status ASI Eksklusif) dengan status gizi balita di wilayah kerja Puskesmas Mencirim Kecamatan Sunggal.

2. Untuk mengetahui hubungan sosio demografi (tingkat pendidikan ibu, penghasilan keluarga, pekerjaan ibu, jumlah anak) dengan status gizi balita di wilayah kerja Puskesmas Mencirim Kecamatan Sunggal.

\section{Hipotesis Penelitian}

1. Ada hubungan antara karakteristik balita (status imunisasi, status ASI Eksklusif) dengan status gizi balita.

2. Ada hubungan antara sosio demografi (tingkat pendidikan ibu, penghasilan keluarga, status pekerjaan ibu, jumlah anak) dengan status gizi balita.

\section{METODE PENELITIAN}

\section{Jenis Penelitian}

Jenis penelitian yang digunakan dalam penelitian ini adalah survey analitik dengan pendekatan Cross Sectional yaitu penelitian untuk menentukan faktorfaktor yang berhubungan dengan status gizi balita.

\section{Lokasi dan Waktu Penelitian}

Penelitian dilakukan di wilayah kerja Puskesmas Mencirim Kecamatan Sunggal pada bulan Juni sampai November 2014.

\section{Populasi dan Sampel \\ Populasi}

Populasi penelitian adalah semua ibu yang memiliki balita berumur 12-59 bulan yang ada di wilayah kerja Puskesmas Mencirim Kecamatan Sunggal yang berjumlah 4189 balita.

\section{Sampel}

Sampel adalah sebagian dari populasi ibu yang memiliki balita di wilayah kerja Puskesmas Rantang Kecamatan Medan Petisah yang berjumlah 102 Orang. Berikut cara pengambilan sampel:

$\mathrm{N}=$ ukuran populasi 


$$
\begin{aligned}
& \mathrm{n}=\text { ukuran sampel } \\
& \mathrm{d}=\text { tingkat kepercayaan yaitu } 0,1 / 10 \% \\
& \mathrm{n}=\frac{\mathrm{N}}{1+\mathrm{N}\left(\mathrm{d}^{2}\right)} \\
& =\frac{4189}{1+4189\left(0.1^{2}\right)} \\
& =\frac{1+42,8}{4180} \\
& =\frac{13,8}{} \\
& =101,66 \\
& =102
\end{aligned}
$$

\section{Metode Pengumpulan Data}

\section{Data Primer}

Data primer merupakan data yang diperoleh dari responden secara langsung dengan metode wawancara yang menggunakan kuesioner yang telah dipersiapkan sebelumnya.

\section{Data Sekunder}

Data sekunder diperoleh dari Puskemas Mencirim Kecamatan Sunggal meliputi gambaran wilayah dan data jumlah balita di Puskesmas tersebut.
Teknik Pengolahan dan Analisa Data

Data yang telah dikumpulkan kemudian diolah secara manual dengan bantuan komputer dan disajikan dalam bentuk tabel distribusi frekuensi.

\section{Analisa Data}

Analisa Univariat

Analisa univariat bertujuan untuk menjelaskan distribusi frekwensi dan persentase dari variabel independen dan variabel dependen.

\section{Analisa Bivariat

\begin{tabular}{|c|c|c|c|}
\hline \multirow{2}{*}{ No } & \multirow{2}{*}{ Identitas Responden } & \multicolumn{2}{|c|}{ Responden } \\
\hline & & $\mathbf{f}$ & $\%$ \\
\hline \multirow[t]{5}{*}{1.} & Kelompok Umur Ibu (Tahun) & & \\
\hline & $<20$ & 6 & 5,9 \\
\hline & $20-35$ & 83 & 81,4 \\
\hline & $>35$ & 13 & 12,7 \\
\hline & Total & 102 & 00 \\
\hline \multirow[t]{3}{*}{2.} & Kelompok Umur Balita (bulan) & & \\
\hline & $\leq 29$ & 53 & 52 \\
\hline & $>29$ & 49 & 48 \\
\hline & Total & 102 & 100 \\
\hline \multirow[t]{3}{*}{3.} & Jenis Kelamin Balita & & \\
\hline & Laki-laki & 56 & 54,9 \\
\hline & Perempuan & 46 & 45,1 \\
\hline & Total & 102 & 100 \\
\hline
\end{tabular} \\ Analisa bivariat dilakukan untuk mencari hubungan kedua variabel independen dan variable dependen. Analisa dilakukan dengan uji chi-square dengan derajat kepercayaan $95 \%(\alpha=5 \%)$, dan hasil uji

\begin{tabular}{|c|c|c|c|}
\hline \multirow{2}{*}{ No } & \multirow{2}{*}{ Karakteristik Balita } & \multicolumn{2}{|c|}{ Responden } \\
\hline & & f & $\%$ \\
\hline \multirow[t]{4}{*}{1.} & Status Imunisasi & & \\
\hline & Lengkap & 84 & 82,4 \\
\hline & Tidak Lengkap & 18 & 17,6 \\
\hline & Total & 102 & 100 \\
\hline \multirow[t]{4}{*}{2} & Status ASI Ekskluif & & \\
\hline & ASI Eksklusif & 15 & 14,7 \\
\hline & Tidak ASI Eksklusif & 87 & 85,3 \\
\hline & Total & 102 & 100 \\
\hline
\end{tabular} statistik akan diperoleh nilai $\mathrm{p}$. Untuk nilai $\mathrm{p}<\alpha$ maka hipotesis diterima}

\section{HASIL DAN PEMBAHASAN}

\section{Identitas Responden}

Tabel 1. Distribusi Frekuensi Identitas Responden di wilayah kerja Puskesmas Mencirim Tahun 2014

Karakteristik Balita

Tabel 2. Distribusi Frekuensi Karakteristik Balita Terhadap Status Gizi di wilayah kerja Pukesmas Mencirim Tahun 2014 
Sosio demografi

Tabel 3. Distribusi Frekuensi Sosio demografi Terhadap Status Gizi di wilayah kerja Pukesmas Mencirim Tahun 2014

\begin{tabular}{|c|c|c|c|}
\hline \multirow{2}{*}{ No } & \multirow{2}{*}{ Sosio demografi } & \multicolumn{2}{|c|}{ Responden } \\
\hline & & Frekuensi & Persentase \\
\hline \multirow[t]{4}{*}{1.} & Tingkat Pendidikan & & \\
\hline & Tinggi & 74 & 72,5 \\
\hline & Rendah & 28 & 27,5 \\
\hline & Total & 102 & 100 \\
\hline \multirow[t]{3}{*}{2.} & Pendapatan Keluarga & & \\
\hline & Tinggi & 47 & 46,1 \\
\hline & Rendah & 55 & 53,9 \\
\hline & Total & 102 & 100 \\
\hline \multirow[t]{3}{*}{3.} & Status Pekerjaan & & \\
\hline & Bekerja & 42 & 41,2 \\
\hline & Tidak bekerja & 60 & 58,8 \\
\hline & Total & 102 & 100 \\
\hline \multirow[t]{4}{*}{4.} & Jumlah Anak & & \\
\hline & $<3$ anak & 53 & 52 \\
\hline & $\geq 3$ anak & 49 & 48 \\
\hline & Total & 102 & 100 \\
\hline
\end{tabular}

\section{Status Gizi Balita}

Tabel 4. Distribusi Status Gizi Balita di wilayah kerja Pukesmas Mencirim 2014

\begin{tabular}{clccc}
\hline \multirow{2}{*}{ No } & \multirow{2}{*}{ Status Gizi } & \multicolumn{2}{c}{ Responden } \\
\cline { 3 - 4 } & & & Frekuensi & Persentase \\
\hline 1. & Baik & & 70 & 68,6 \\
2. & Kurang & Total & 32 & 31,4 \\
\hline & & 102 & $\mathbf{1 0 0}$ \\
\hline
\end{tabular}

Analisa Bivariat

Karakteristik Balita

Tabel 5. Tabulasi Silang Status Imunisasi Dengan Status Gizi Balita di wilayah kerja Puskesmas Rantang 2010

\begin{tabular}{|c|c|c|c|c|c|c|c|c|}
\hline \multirow{3}{*}{ No } & \multirow{3}{*}{ Status Imunisasi } & \multicolumn{4}{|c|}{ Status Gizi Balita } & \multicolumn{2}{|c|}{ Jumlah } & \multirow{3}{*}{$\mathrm{P}$} \\
\hline & & \multicolumn{2}{|c|}{ Baik } & \multicolumn{2}{|c|}{ Kurang } & \multirow{2}{*}{ f } & \multirow{2}{*}{$\%$} & \\
\hline & & $\mathrm{f}$ & $\%$ & $\mathrm{f}$ & $\%$ & & & \\
\hline 1. & Lengkap & 64 & 65,1 & 20 & 17,3 & 84 & 82,4 & 0,001 \\
\hline 2. & Tidak lengkap & 6 & 6,1 & 12 & 11,5 & 18 & 17,6 & \\
\hline & Total & 70 & 71,2 & 32 & 28,8 & 102 & 100 & \\
\hline
\end{tabular}

Tabel 6. Tabulasi Silang Status ASI Eksklusif Dengan Status Gizi Balita di wilayah kerja Puskesmas Rantang 2010

\begin{tabular}{|c|c|c|c|c|c|c|c|c|}
\hline \multirow{3}{*}{ No } & \multirow{3}{*}{ Status ASI Eksklusif } & \multicolumn{4}{|c|}{ Status Gizi Balita } & \multicolumn{2}{|c|}{ Jumlah } & \multirow{3}{*}{$\mathrm{P}$} \\
\hline & & \multicolumn{2}{|c|}{ Baik } & \multicolumn{2}{|c|}{ Kurang } & \multirow[b]{2}{*}{$\mathrm{f}$} & \multirow[b]{2}{*}{$\%$} & \\
\hline & & $\mathrm{f}$ & $\%$ & $\mathrm{f}$ & $\%$ & & & \\
\hline 1. & ASI Eksklusif & 15 & 14,7 & 0 & 0 & 15 & 14,7 & 0,017 \\
\hline 2. & Tidak ASI Eksklusif & 55 & 48.5 & 32 & 36,8 & 87 & 85,3 & \\
\hline & Total & 70 & 63,2 & 32 & 38,8 & 102 & 100 & \\
\hline
\end{tabular}

Sosio demografi

Tabel 7. Tabulasi Silang Tingkat Pendidikan Ibu Dengan Status Gizi Balita di wilayah kerja Puskesmas Mencirim Tahun 2014

\begin{tabular}{|c|c|c|c|c|c|c|c|c|}
\hline \multirow{3}{*}{ No } & \multirow{3}{*}{ Tingkat Pendidikan Ibu } & \multicolumn{4}{|c|}{ Status Gizi Balita } & \multicolumn{2}{|c|}{ Jumlah } & \multirow{3}{*}{$\mathrm{P}$} \\
\hline & & \multicolumn{2}{|c|}{ Baik } & \multicolumn{2}{|c|}{ Kurang } & \multirow{2}{*}{$\mathrm{f}$} & \multirow{2}{*}{$\%$} & \\
\hline & & $\mathrm{f}$ & $\%$ & $\mathrm{f}$ & $\%$ & & & \\
\hline 1. & Tinggi & 63 & 64,2 & 11 & 8,3 & 74 & 72,5 & 0,000 \\
\hline 2. & Rendah & 7 & 7,0 & 21 & 20,5 & 28 & 27,5 & \\
\hline & Total & 70 & 71,2 & 32 & 28,6 & 102 & 100 & \\
\hline
\end{tabular}


Tabel 8. Tabulasi Silang Pendapatan Keluarga Dengan Status Gizi Balita di wilayah kerja Puskesmas Mencirim 2014

\begin{tabular}{|c|c|c|c|c|c|c|c|c|}
\hline \multirow{3}{*}{ No } & \multirow{3}{*}{ Pendapatan Keluarga } & \multicolumn{4}{|c|}{ Status Gizi Balita } & \multicolumn{2}{|c|}{ Jumlah } & \multirow{3}{*}{$\mathrm{P}$} \\
\hline & & \multicolumn{2}{|c|}{ Baik } & \multicolumn{2}{|c|}{ Kurang } & \multirow[b]{2}{*}{$\mathrm{f}$} & \multirow{2}{*}{$\%$} & \\
\hline & & $\mathrm{f}$ & $\%$ & $\mathrm{~F}$ & $\%$ & & & \\
\hline 1. & Tinggi & 38 & 54,2 & 9 & 6,1 & 47 & 46,1 & 0,006 \\
\hline 2. & Rendah & 32 & 45,7 & 23 & 22,4 & 55 & 53,9 & \\
\hline & Total & 70 & 73,4 & 32 & 28,5 & 102 & 100 & \\
\hline
\end{tabular}

Tabel 9. Tabulasi Silang Status Pekerjaan Ibu Dengan Status Gizi Balita di wilayah kerja Puskesmas Mencirim Tahun 2014

\begin{tabular}{|c|c|c|c|c|c|c|c|c|}
\hline \multirow{3}{*}{ No } & \multirow{3}{*}{ Status Pekerjaan Ibu } & \multicolumn{4}{|c|}{ Status Gizi Balita } & \multicolumn{2}{|c|}{ Jumlah } & \multirow{3}{*}{$\mathrm{P}$} \\
\hline & & \multicolumn{2}{|c|}{ Baik } & \multicolumn{2}{|c|}{ Kurang } & \multirow{2}{*}{$\mathrm{f}$} & \multirow{2}{*}{$\%$} & \\
\hline & & $\mathrm{F}$ & $\%$ & $\mathrm{~F}$ & $\%$ & & & \\
\hline 1. & Bekerja & 34 & 34,7 & 8 & 6,5 & 42 & 41,2 & 0,010 \\
\hline 2. & Tidak bekerja & 36 & 36,7 & 24 & 22,1 & 60 & 58,8 & \\
\hline & Total & 70 & 71,4 & 32 & 28,6 & 102 & 100 & \\
\hline
\end{tabular}

Tabel 10. Tabulasi Silang Jumlah Anak Dengan Status Gizi Balita di wilayah kerja Puskesmas Mencirim tahun 2014

\begin{tabular}{|c|c|c|c|c|c|c|c|c|}
\hline \multirow{3}{*}{ No } & \multirow{3}{*}{ Jumlah Anak } & \multicolumn{4}{|c|}{ Status Gizi Balita } & \multicolumn{2}{|c|}{ Jumlah } & \multirow{3}{*}{$\mathrm{P}$} \\
\hline & & \multicolumn{2}{|c|}{ Baik } & \multicolumn{2}{|c|}{ Kurang } & \multirow{2}{*}{$\mathrm{f}$} & \multirow{2}{*}{$\%$} & \\
\hline & & $\mathrm{F}$ & $\%$ & $\mathrm{~F}$ & $\%$ & & & \\
\hline 1. & $<3$ anak & 34 & 34,7 & 19 & 15,3 & 53 & 52 & 0,587 \\
\hline 2. & $\geq 3$ anak & 36 & 36,7 & 13 & 12,2 & 49 & 48 & \\
\hline & Total & 70 & 71,4 & 32 & 27,5 & 102 & 100 & \\
\hline
\end{tabular}

$\mathrm{X}^{2}=0,588 \quad \mathrm{df}=1$

\section{Pembahasan}

Hasil analisa statistik dengan uji chi square diperoleh $\mathrm{p}$ (fisher's exact) $=0,001$ menunjukkan bahwa ada hubungan antara status imunisasi dengan status gizi balita. Anak yang diimunisasi berarti diberi kekebalan terhadap suatu penyakit tertentu, jadi tujuan imunisasi adalah untuk mencegah penyakit dan kematian balita yang disebabkan oleh wabah yang sering berjangkit. Beberapa data menunjukkan bahwa penyebab utama dari penyakit, kematian dan terhambatnya pertumbuhan anak merupakan kompleksitas hubungan timbal balik antara status gizi dan infeksi (Karjati, 2001).

Balita yang diberi imunisasi lengkap mempunyai daya tahan tubuh lebih tinggi dari pada balita yang tidak mendapat imunisasi lengkap. Balita dengan status imunisasi tidak lengkap lebih mudah terserang penyakit, jika status imunisasi balita tidak lengkap maka balita dapat mudah terserang penyakit yang akan mempengaruhi keadaan tubuh serta pola makan balita tersebut. Pada anak yang menderita penyakit infeksi terjadi gangguan pada pertahanan tubuh dan sebagai akibatnya akan terjadi penurunan berat badan dalam waktu yang singkat sehingga dapat menyebabkan kekurangan gizi. Tidak menutup kemungkinan balita dengan status imunisasi tidak lengkap berstatus gizi baik, hal ini bisa disebabkan konsumsi makanan dengan gizi baik yang diberikan ibu balita.

hasil analisa dengan uji chi square antara pemberian Asi Eksklusif dengan status gizi balita diperoleh $\mathrm{p}$ (fisher's exact) $=0,017$ yang berarti ada hubungan antara status ASI eksklusif dengan status gizi balita. Menurut penelitian Ginting (2005) bahwa pemberian ASI eksklusif pada bayi berhubungan dengan status gizi pada balita. Balita yang tidak mendapat ASI Eksklusif kemungkinan 2,5 kali lebih besar kemungkinan menderita gangguan gizi dibanding dengan anak yang pernah memperoleh ASI Eksklusif.

Balita dengan ASI Eksklusif tidak mudah terserang penyakit-penyakit infeksi yang sering menyerang balita yang nantinya akan mempengaruhi status gizi balita. Akan tetapi tidak semua balita yang tidak ASI Eksklusif berstatus gizi kurang ada juga balita dengan status gizi baik, hal ini juga bisa dipengaruhi faktor lain, seperti asupan gizi yang baik, pola asuh yang baik dari ibu balita tersebut.

Sementara hasil analisa dengan uji chi square antara tingkat pendidikan ibu dengan status gizi balita menunjukkan hubungan yang sangat signifikan pada $\mathrm{p}=$ 0,000. Tingkat pendidikan turut pula menentukan mudah tidaknya seseorang menyerap dan memahami pengetahuan gizi yang mereka peroleh. Hal ini bisa dijadikan landasan untuk membedakan metode penyuluhan yang tepat. Untuk kepentingan gizi keluarga, pendidikan diperlukan agar seseorang lebih tanggap terhadap adanya masalah gizi didalam keluarga dan bisa mengambil tindakan secepatnya (Suhardjo, 2003). 
Pendidikan ibu berpengaruh terhadap pengetahuan ibu tentang cara mengasuh anak yang akan membentuk pola asuh. Semakin tinggi pendidikan ibu, diharapkan pola asuh terhadap anak semakin baik (Oktarina, 2008). Semakin tinggi pendidikan ibu maka akan semakin baik pengetahuan ibu untuk menentukan konsumsi makanan yang baik yang dibutuhkan balita dimasa pertumbuhan balita. Meskipun pendidikan ibu tinggi tidak menutup kemungkinan balita menderita gangguan gizi. Hal ini di duga disebabkan karena pendidikan ibu yang tinggi bukan satu-satunya faktor yang menjadikan balita terhindar dari kejadian gizi buruk, tetapi ada beberapa faktor lain seperti salah satunya adalah penyakit infeksi. Adanya penyakit infeksi seperti ISPA maupun diare pada balita menyebabkan makanan yang dikonsumsi balita akan terhambat penyerapannya dan energi didapatkan dari makanan akan habis atau berkurang.

Berdasarkan hasil analisa dengan uji chi square diperoleh $\mathrm{p}=0,006$ yang berarti ada hubungan antara pendapatan keluarga dengan status gizi balita, yang berarti semakin tinggi tingkat pendapatan keluarga, maka semakin baik kondisi kesehatan balita. Pendapatan keluarga sangat mempengaruhi konsumsi makan sehari-hari. Apabila pendapatan rendah maka makanan yang dikonsumsi tidak mempertimbangkan nilai gizi, tetapi nilai materi lebih menjadi pertimbangan. Namun demikian tidak menutup kemungkinan bahwa keluarga yang berpenghasilan rendah dapat mengkonsumsi makanan yang mempunyai nilai gizi baik (Yulius, 2008). Hal ini sejalan dengan penelitian Andarwati (2007) didesa Purwojati kecamatan Kertek Wonosobo, dimana terdapat hubungan yang bermakna antara pendapatan keluarga dengan status gizi balita $(\mathrm{p}=$ 0,002).

Tingkat pendapatan ikut menentukan jenis pangan apa yang akan dibeli dengan adanya tambahan uang. Semakin tinggi pendapatan, semakin besar pula persentase dari penghasilan tersebut dipergunakan untuk membeli buah, sayur mayur dan berbagai jenis bahan pangan lainnya (Andarwati, 2003). Keluarga dengan pendapatan tinggi akan lebih mudah memenuhi kebutuhan pangannya. Tapi tidak menutup kemungkinan balita dengan pendapatan keluarga tinggi menderita gangguan gizi. Keluarga dengan pendapatan rendah menyebabkan orang tidak mampu membeli pangan dalam jumlah yang diperlukan dan kurang memperhatikan nilai gizi. Namun demikian tidak menutup kemungkinan bahwa keluarga yang berpenghasilan rendah dapat mengkonsumsi makanan yang mempunyai nilai gizi baik.

Hasil uji statistik dengan uji chi square antara status pekerjaan ibu dengan status gizi balita diperoleh $\mathrm{p}=$ 0,010 yang berarti ada hubungan antara status pekerjaan ibu dengan status gizi balita. Menurut Solihin (2003) salah satu faktor yang dapat mempengaruhi terjadinya kurang gizi adalah para ibu yang menerima pekerjaan tetap sehingga harus meninggalkan balitanya dari pagi sampai sore, anak-anak terpaksa ditinggalkan dirumah sehingga jatuh sakit dan tidak mendapatkan perhatian, dan pemberian makanan tidak dilakukan dengan semestinya.

Hal ini sejalan dengan penelitian Arif (2006) di Kelurahan Sekaran Kecamatan Gunung Pati Semarang yang menemukan bahwa ada hubungan antara status gizi dengan status pekerjaan ibu $(\mathrm{p}=0,000)$. Salah satu dampak negatif yang dikhawatirkan timbul sebagai akibat dari keikutsertaan ibu-ibu pada kegiatan di luar rumah adalah keterlantaran anak terutama anak balita, padahal masa depan kesehatan anak dipengaruhi oleh pengasuhan dan keadaan gizi sejak usia bayi sampai anak berusia 5 tahun merupakan usia penting, karena pada umur tersebut anak belum dapat melayani kebutuhan sendiri dan bergantung pada pengasuhnya. Oleh karena itu alangkah baiknya balita yang ditinggalkan dapat dipercayakan kepada pengasuh atau anggota keluarga yang lain untuk dirawat dan diberi konsumsi makanan yang baik.

Ibu yang bekerja akan memiliki waktu yang lebih sedikit untuk memperhatikan kondisi dan pola makan balitanya. Ibu lebih mempercayakan segala sesuatunya pada pengasuhnya karena dia tidak memiliki cukup waktu untuk mengurusi anaknya seharian. Sebaliknya ibu yang tidak bekerja memiliki waktu lebih untuk memperhatikan kondisi dan pola makan anaknya.

Hasil penelitian menunjukkan bahwa jumlah anak tidak ada hubungan antara jumlah anak dengan status gizi balita yaitu $\mathrm{p}=0,587$. Hal ini sejalan dengan penelitian Marlina (2008) di Kelurahan Sicanang Belawan dimana tidak terdapat hubungan yang bermakna antara status gizi balita dengan jumlah anak dalam keluarga ( $\mathrm{p}=$ 0,842).Menurut Lidia (2003) status gizi balita bukan semata-mata disebabkan oleh faktor jumlah anak dalam keluarga melainkan banyak faktor. Salah satunya pola asuh keluarga terhadap balita, dimana kemungkinan pola asuh yang kurang baik mempengaruhi status gizi balita sehingga walaupun jumlah tanggungan keluarga sedikit, kondisi status gizi balita dapat terancam pula. Selain itu status imunisasi balita, dimana kelengkapan imunisasi sangat berpengaruh terhadap kesehatan balita sehingga walaupun balita pada keluarga dengan jumlah anak yang cukup banyak tidak terancam mengalami gizi kurang.

\section{SIMPULAN DAN SARAN}

\section{Simpulan}

1. Berdasarkan variabel karakteristik balita.

a. Ada hubungan antara status imunisasi dengan status gizi balita

b. Ada hubungan antara status ASI Eksklusif dengan statu gizi balita

2. Berdasarkan variabel sosio demografi

a. Ada hubungan antara tingkat pendidikan dengan status gizi balita.

b. Ada hubungan antara pendapatan keluarga dengan status gizi balita.

c. Ada hubungan antara status pekerjaan ibu dengan status gizi balita.

d. Tidak ada hubungan antara jumlah anak dengan status gizi balita.

\section{Saran}

Bagi Puskesmas Mencirim untuk mengadakan penyuluhan bagi ibu balita mengenai peningkatan gizi yang baik untuk balita. 
1. Perlu dilakukan penelitian lanjutan tentang Perilaku dan motivasi ibu dalam pemenuhan gizi anak balita.

\section{DAFTAR PUSTAKA}

Adisasmito.2010.Sistem Kesehatan.PT Rajagrafindo Persana:Jakarta

Administrator.2009.Gizi Buruk Ancaman Generasi Yang Hilang

Arisman.2007.Gizi Dalam Daur Kehidupan.Cetakan IIEGC.Jakarta

Balit-bankes Depkes RI.2008.Upaya Perbaikan Masalah Gizi

Bambang.2011.Super Baby Directory. Flash Books: Jogjakarta

Budiasih.2008.Hand Book Ibu Menyusui.PT Karya Kita:Bandung

Hadi, Haman.2005.Beban Gnda Masalah Gizi dan Implikasinya Terhadap Kebijakan Pembangunan Kesehatan Nasional
http://www.Profil Depkes Sumatera Utara.com/2011

Krisnatuti,dkk.2000.Menyiapkan Makanan Pendamping ASI.Puspa Swara:Jakarta

Mawaddah.2009.Pengertian Gizi Buruk.

Notoatmodjo.,2010. Promosi Kesehatan Teori dan Aplikasi, Rineka Cipta, Jakarta

Pemko Medan.2012.Jumlah Balita Penderita Gizi Buruk

Prasetyono.2009.Buku Pintar ASI Eksklusif.Diva Press:Jogjakarta

Profil Kesehatan Kabupaten Pakpak Bharat.2010

Ramadhan.2010.Bahaya Gizi Buruk.

Riksani.2012.Keajaiban ASI.Niaga Swadaya:Jakarta Timur

Roesli,U.2008.Mengenal ASI Eksklusif.Pustaka Bunda:Jakarta

Sholin.2009.Ancaman Generasi yang Hilang.

Soekatri,M.2011.Gizi Seimbang Dalam Daur Kehidupan.PT Gramedia Pustaka Utama:Jakarta

Suwandi MS.2009.Jurnal Kedokteran dan Kesehatan. 